\title{
Organic and elemental carbon bound to particulate matter in the air of printing office and beauty salon
}

\author{
Patrycja Rogula-Kopiec ${ }^{1,1}$, Józef S. Pastuszka², Wioletta Rogula-Kozłowska ${ }^{1,3}$, and Walter \\ Mucha $^{2}$ \\ ${ }^{1}$ Institute of Environmental Engineering, Polish Academy of Sciences, 34 M. Skłodowska-Curie St., \\ 41-819 Zabrze, Poland \\ 2 Department of Air Protection, Silesian University of Technology, 22B Konarskiego St., 44-100 \\ Gliwice, Poland \\ ${ }^{3}$ The Main School of Fire Service, Faculty of Fire Safety Engineering, 52/54 Słowackiego St. 01-629 \\ Warsaw, Poland
}

\begin{abstract}
The aim of this study was to determine the role of internal sources of emissions on the concentrations of total suspended particulate matter (TSP) and its sub-fraction, so-called respirable PM (PM4; fraction of particles with particle size $\leq 4 \mu \mathrm{m})$ and to estimate to which extent those emissions participate in the formation of PM-bound elemental (EC) and organic (OC) carbon in two facilities - one beauty salon and one printing office located in Bytom (Upper Silesia, Poland). The average concentration of $\mathrm{PM}$ in the printing office and beauty salon during the 10-day measurement period was 10 and $4\left(\mathrm{PM}_{4}\right)$ and 8 and 3 (TSP) times greater than the average concentration of PM fractions recorded in the same period in the atmospheric air; it was on average: $204 \mu \mathrm{g} / \mathrm{m}^{3}\left(\mathrm{PM}_{4}\right)$ and $319 \mu \mathrm{g} / \mathrm{m}^{3}$ (TSP) and $93 \mu \mathrm{g} / \mathrm{m}^{3}\left(\mathrm{PM}_{4}\right)$ and $136 \mu \mathrm{g} / \mathrm{m}^{3}$ (TSP), respectively. OC concentrations determined in the printing office were $38 \mu \mathrm{g} / \mathrm{m}^{3}\left(\mathrm{PM}_{4}\right)$ and $56 \mu \mathrm{g} / \mathrm{m}^{3}$ (TSP), and those referring to EC: $1.8 \mu \mathrm{g} / \mathrm{m}^{3}$ (PM4) and 3.5 $\mu \mathrm{g} / \mathrm{m}^{3}$ (TSP). In the beauty salon the average concentration of OC for $\mathrm{PM}_{4}$ and TSP were 58 and $75 \mu \mathrm{g} / \mathrm{m}^{3}$, respectively and in case of EC - 3.1 and $4.7 \mu \mathrm{g} / \mathrm{m}^{3}$, respectively. The concentrations of OC and $\mathrm{EC}$ within the those facilities were approximately 1.7 (TSP-bound EC, beauty salon) to 4.7 (TSP-bound OC, printing office) times higher than the average atmospheric concentrations of those compounds measured in both PM fractions at the same time. In both facilities the main source of TSP- and $\mathrm{PM}_{4}$-bound $\mathrm{OC}$ in the indoor air were the chemicals - solvents, varnishes, paints, etc.
\end{abstract}

${ }^{1}$ Corresponding author: patrycja.rogula-kopiec@ipis.zabrze.pl 


\section{Introduction}

The quality of indoor air in different types of rooms depends among others on the physiological activity of people staying there, the type and intensity of the functions served within such rooms and the type and effectiveness of the ventilation system. In service facilities, where food is prepared (cooking, frying), or coal furnaces or fireplaces are being used for heating purposes, and most of all where people smoke tobacco, the quality of indoor air is much worse compared to outdoor one. These concern, among other, air pollution by particulate matter, PM, and especially its fine particles [1-5]. Fine PM particles freely migrate into rooms interiors, which means that their concentration in the indoor air should be similar (or greater) compared to its ambient concentrations (outdoor air). This tendency can occur depending on the presence and effectiveness of the internal sources of PM and other pollutants emission (eg. some gases reacting with each other and with PM components), room airing (preventing or promoting accumulation of PM inside the building) or the efficiency of room ventilation system [6-10].

Due to the harmfulness associated with the emissions of different types of air pollutants in different factories and other workplaces, the concentrations of specific substances, including PM, are being routinely measured. However, there are many facilities, where, despite heavily polluted air, there is no standards or legal requirement warranting the assessment of this pollution. This anticipated, significant air pollution in the room interiors can be caused by both: the fact that such objects are located in highly polluted region, (where at certain, described above conditions the accumulation of indoor pollution occurs) and by the presence of internal sources of emissions. The need to recognize the quality of indoor air in such areas is objectively justified when both mentioned sources of emissions (the outdoor and the indoor one) are constantly present.

Silesia Agglomeration is one of Europeans regions with the most polluted air. Concentrations of PM and PM components in its urban locations in some periods are several times higher compared to those meet in the big cities of Western, Northern and Southern Europe [11-13]. Compared to other Polish and European regions Silesia region is also heavily industrialized and urbanized. Within the Upper Silesia Agglomeration, which consists of 14 cities, the total number of its residents exceeds 2 million people, more than $60 \%$ of the working population employed in the so-called services sector. Among service facilities, where significant internal sources of air pollution are normally found printing office and beauty salons are definitely the leading one. In such places, due to the nature of the performed services, a very high concentrations of various types of organic pollutants can be suspected. Given the fact that Silesia region is characterized by a very high concentrations of PM and relatively high concentrations of PM-bound carbon $[13,14]$, and interesting topic was to recognize to which extent the activities carried out in such facilities enhance the formation and structure of PM-bound carbon compounds in the indoor air.

The PM-related Total Carbon (TC) consists of elemental carbon (EC) and organic carbon (OC) $[15,16]$. PM-bound EC is mostly of primary origin, emitted mainly as a result of incomplete combustion of solid fuels, or the pyrolysis of biological material [17], while the PM-bound OC in a one part consist of primary matter (primary organic carbon, POC), and partly is the product of the transformation of gaseous precursors in the air (secondary organic carbon, SOC) $[16,18,19]$. The sources of POC include combustion processess, including the combustion of: gasoline (in internal combustion engines), coal from biomass and also vegetation, including pollen, spores, crushed plant material, as well as bacteria and viruses [20]. The intensity of SOC creation depends on the direction and dynamics of the chemical reactions occurring in the air, in particular the transformation of volatile organic compounds (VOCs) [21]. The expected, significant emission of VOCs, but also PM-bound OC will probably occur in rooms where the printing is being carried out, using various 
types of paints, solvents and but also laser printing, welding, etc. but also there, where different types of treatments and beauty services are being carried out using the chemicals rich in organic acids, phenols, hydrocarbons, alcohols, but also those requiring the usage of laser, milling machines, and so on. Such activities will influence not only the changes in the contribution of PM-bound $\mathrm{OC}$ and $\mathrm{EC}$ in the indoor air in relation to atmospheric air but also the contributions of POC and SOC in PM-bound OC.

The aim of the study was to determine the role of internal sources of OC and EC on the concentrations of PM-bound EC and OC in two facilities - one beauty salon and one printing office located in a city of Upper Silesia (Poland).

\section{Materials and methods}

To conduct this study, a single printing office and beauty salon were typed. Both were located in Bytom city (one of the 14 cities located in Silesia Agglomeration with an area of $69 \mathrm{~km}^{2}$ and 170 thousand of inhabitants). Both facilities were located within the same housing estate, surrounded by the typical settlement, without any large source of emission in the closest proximity, like industrial/manufacturing facility or traffic artery. Selected printing office providing printing services like large format printing on a variety types of paper and films, but also other services like thermal treatment (welding) the edges of the selected products (banners, posters). The measurements campaign was conducted in a hall with an area of about $50 \mathrm{~m}^{2}$, which run printing, at a distance of about $3 \mathrm{~m}$ in a straight line from the printing machine. The hall is located in a new building, which remaining part (about $\left.15 \mathrm{~m}^{2}\right)$ is a customer service, social room $\left(10 \mathrm{~m}^{2}\right)$ and a toilet. The building has a natural ventilation system and two large (PVC) windows on each wall. In the summer, when the measurements were carried out the door between the hall and the office together with the exit door (emergency exits from the hall) and windows were constantly opened. All printouts from the machine are hanging to dry in the open air inside the hall, at the time when the machine is kept on a standby, for example when cyclical printing areas are sprayed with the appropriate solvent. The beauty salon is located in a residential building, adopted for service activities. Measurements were carried out in one among five rooms belonging to the salon (in each a different kind of treatments is being run) - the office, where pedicure and manicure are performed. The room has an area of about $30 \mathrm{~m}^{2}$. The room is equipped with a seat for customers and a beauty table. Measurements were conducted at a distance of approximately $3 \mathrm{~m}$ from the table. The building is equipped with a gravity ventilation and PVC windows, most of which are closed, and the room is ventilated only after the working day is end (after 18.00). During work a beautician uses miling machine, nailfiles, and a number of cosmetics containing hydrocarbons, alcohols, esters, phenols, and the like. Nail coatings and gels are cured under UV lamp.

PM samples were collected in the period of 18-31 July 2015 in the salon and in the period of 18-29 August 2015 in the printing office in a 8-hour cycles, usually between 10.00-18.00, (normal working day). All measurements were performed during summer period, because in winter the concentrations of $\mathrm{PM}$ and $\mathrm{PM}$-bound $\mathrm{OC}$ and $\mathrm{EC}$ are overshadowed by the emissions from the combustion of coal and biomass for heating purposes [14,16]; this emission is very high in this region and masks the influence of other sources of PM and PM-bound carbon components. In each measurement site a set of two identical, calibrated PM samplers were used, one collecting (PM4) and the second one collecting (TSP). Such set was located inside the room as well as the outside. In this arrangement, at each measurement point within a single room, ten measurements were performed using Gilian sampling pumps (Sensidyne, St. Petersburg, FL).

Samples were collected on Whatman quartz filters (QMA, ø25 mm) (GE Medical Systems Polska, Life Sciences, Warsaw, Poland). The mass of a PM sample was 
determined by filter weighing on a microscale (resolution of $1 \mu \mathrm{g}$ ) (Radwag; Radom, Poland) before and after the exposure. Before weighing, chemical composition on the filter was conditioned in the weighing room for $48 \mathrm{~h}$ under constant conditions (humidity of $45 \pm 5 \%$ and air temperature of $\left(20 \pm 2^{\circ} \mathrm{C}\right)$. After the collection of PM samples and gravimetric analysis, a $1.5 \mathrm{~cm}^{2}$ fraction of each collected sample was taken for tests on organic carbon (OC) and elemental carbon (EC) contents using a thermal-optical method. The analytical methods including precision verification procedures, has been described in detail elsewhere [16].

\section{Results and discussion}

Inside the beauty salon and printing office the 8-h concentration of PM4 and TSP as well as their carbon components (TSP- and PM4-bound OC and EC) were generally significantly higher than in atmospheric air. In both locations the differences in the 8-h concentrations between the indoor and outdoor were statistically significant $(p<0.05$ at $\mathrm{p}_{\text {assump. }}=0.05$; U Mann-Whitney test). Those concern both the PM fractions and their carbonaceous species. In the printing office the average concentration of PM4 and TSP in the indoor air was 10 times and 8 times higher compared to outdoor concentrations, respectively; analogous relationship concern beauty salon were this differences were 4 (PM4) and 3 (TSP) times, respectively - Table 1. In case of TSP- and PM4-bound OC the ratios of the average concentrations of those fractions between the printing office's and a beauty salon's interiors and ambient air do not exceed 5; and for EC it was in range 1.662.83 (Table 1).

In both facilities the impact of internal emission sources of PM and PM-bound OC and EC on their indoor concentrations was clearly marked. The 8-h concentration of PM and PM-bound OC and EC in both facilities were not correlated with the 8-h concentrations of PM and PM-bound OC and EC measured at the same time outside those buildings, which excludes the substantial influence of atmospheric air on indoor one (Table 2). In the printing office the effect of the internal emissions on PM and PM-bound OC/EC concentrations was much more pronounced than in the beauty salon and much clearer in case of PM than PM-bound OC/EC.

In the printing office the relative (compared to atmospheric/outdoor air) increase in the concentrations of indoor PM and PM-bound OC wasn't comparable. So, the increase in the concentrations of PM in the indoor air may be related to the workers and clients activities within the printing office, the erosion of different mechanical elements of the printing machine, and the emission associated with the processing of finished prints, etc. Thus, within such area the concentration of other than EC and OC components (like non determined in this work minerals, metals and metalloids, etc.), increase probably even greater (compared to the outdoor air concentrations). It is also very likely that in the specific conditions of high concentrations of ozone and ammonia typical for printing office interiors [22] and the free flow of sunlight from the outside at the same time (open doors and windows) the transformations of other than VOCs (the precursors of OC) compounds emitted during the printing and thermal processing of prints, like the precursors of secondary (inorganic) aerosol, ie. nitrogen oxides. The 8-h concentrations of TSP- and PM4-bound OC in indoor air in the printing office were not correlated with the 8-h concentrations of TSP and PM4, which confirms that the increase in the 8-h concentration of PM in the air did not proceed in same way as in case of 8 -h OC concentrations (Table 2). 
In the beauty salon, this situation was different. A strong and positive correlations between TSP and TSP-bound OC as well as in case of PM4 and PM4-bound OC testify that their 8-h levels grew at a similar (proportional) rate. In addition, an increase in the concentrations of PM-bound OC in indoor air vs. outdoor air was more pronounced than the increase in the concentrations of PM (Table 1). In case of beauty salon a strong and direct impact of emissions of various kinds of organic compounds that are components of the cosmetics were reflected by an increase in the concentration of OC bounded to both: fine and coarse PM (the contribution of PM4 in TSP in indoor air was about $65 \%$ - Table 1 and $\mathrm{R} 2$ for the correlation between the 8-h concentrations of PM4-bound OC and TSP-bound $\mathrm{OC}$ in the printing office came to 0.9 - Table 2).

In both facilities the effect of the internal activity on the concentration of indoor PMbound EC was strictly observed. In case of printing office it was probably the result of EC emission during the thermal processing of prints (welding) done on different kinds of foils (the correlation between the 8-h concentrations of PM4 and PM4-bound EC and the lack of correlation between the 8-h concentrations of TSP and TSP-bound EC). In the beauty salon interiors, the probably explanation for almost three times higher concentrations of indoor EC concentrations compared to outdoor ones for both fine and coarse PM is almost continuous use the incense and scented candles [23,24].

Table 1. The concentrations and ratios of $\mathrm{PM}_{4}$, TSP and related carbon compounds (elemental, EC and organic, $\mathrm{OC}$ ) in the printing office and in the beauty salon.

\begin{tabular}{|c|c|c|c|c|c|c|c|c|c|}
\hline a)PRINTING OFFICE & $\mathrm{PM}_{4}$ & $\mathrm{OC}$ & EC & TSP & $\mathrm{OC}$ & EC & $\begin{array}{l}\mathrm{PM}_{4} / \\
\mathrm{TSP}\end{array}$ & b) $\mathrm{OC} / \mathrm{OC}$ & ${ }^{c)} \mathrm{EC} / \mathrm{EC}$ \\
\hline \multirow{2}{*}{$\begin{array}{l}\text { Ave } \pm \text { st.dev. } \\
\text { Indoor }\end{array}$} & $203.87 \pm$ & $38.05 \pm$ & $1.83 \pm$ & $318.95 \pm$ & $56.21 \pm$ & $3.46 \pm$ & $0.65 \pm$ & $0.68 \pm$ & $0.53 \pm$ \\
\hline & 320.55 & 9.10 & 0.84 & 456.46 & 8.79 & 1.26 & 0.19 & 0.14 & 0.16 \\
\hline \multirow{2}{*}{$\begin{array}{l}\text { Ave } \pm \text { st.dev. } \\
\text { Outdoor }\end{array}$} & $19.36 \pm$ & $10.89 \pm$ & $0.86 \pm$ & $33.48 \pm$ & $13.26 \pm$ & $1.40 \pm$ & $0.58 \pm$ & $0.84 \pm$ & $0.59 \pm$ \\
\hline & 7.46 & 2.38 & 0.54 & 10.46 & 3.74 & 0.64 & 0.10 & 0.12 & 0.16 \\
\hline \multirow{2}{*}{$\begin{array}{l}\text { Ave } \pm \text { st.dev. } \\
\text { Indoor/Outdoor }\end{array}$} & $10.29 \pm$ & $3.60 \pm$ & $2.83 \pm$ & $8.21 \pm$ & $4.67 \pm$ & $2.81 \pm$ & & & \\
\hline & 15.53 & 0.97 & 1.90 & 10.03 & 1.84 & 1.32 & & & \\
\hline BEAUTY SALON & $\mathrm{PM}_{4}$ & $\mathrm{OC}$ & EC & TSP & $\mathrm{OC}$ & EC & $\begin{array}{l}\mathrm{PM}_{4} / \\
\mathrm{TSP}\end{array}$ & ${ }^{\mathrm{b})} \mathrm{OC} / \mathrm{OC}$ & ${ }^{{ }^{)}} \mathrm{EC} / \mathrm{EC}$ \\
\hline \multirow{2}{*}{$\begin{array}{l}\text { Ave } \pm \text { st.dev. } \\
\text { Indoor }\end{array}$} & $92.84 \pm$ & $58.00 \pm$ & $3.12 \pm$ & $135.99 \pm$ & $75.38 \pm$ & $4.66 \pm$ & $0.68 \pm$ & $0.79 \pm$ & $0.67 \pm$ \\
\hline & 50.44 & 24.82 & 2.45 & 59.95 & 32.24 & 3.01 & 0.15 & 0.11 & 0.22 \\
\hline \multirow{2}{*}{$\begin{array}{l}\text { Ave } \pm \text { st.dev. } \\
\text { Outdoor }\end{array}$} & $24.81 \pm$ & $14.76 \pm$ & $1.68 \pm$ & $43.66 \pm$ & $20.27 \pm$ & $2.92 \pm$ & $0.59 \pm$ & $0.72 \pm$ & $0.58 \pm$ \\
\hline & 5.80 & 5.83 & 0.34 & 10.12 & 3.85 & 0.66 & 0.16 & 0.23 & 0.10 \\
\hline \multirow{2}{*}{$\begin{array}{l}\text { Ave } \pm \text { st.dev. } \\
\text { Indoor/Outdoor }\end{array}$} & $3.88 \pm$ & $4.66 \pm$ & $1.81 \pm$ & $3.37 \pm$ & $3.82 \pm$ & $1.66 \pm$ & & & \\
\hline & 2.19 & 2.74 & 1.15 & 2.06 & 1.76 & 1.08 & & & \\
\hline
\end{tabular}

a) in each facility, both inside and outside, the number of measurement data for one fraction $n=10$; Total number of samples in each facility $n=40$;

b) The mass contribution of $\mathrm{PM}_{4}$-bound OC in the TSP-bound OC

c) the contribution of PM4-bound EC in the TSP-bound EC

Table 2. The coefficient of determination $\left(\mathrm{R}^{2}\right)$ indicating the strength of the linear correlation between the 8-h concentrations of PM4, TSP and their carbon components (elemental, EC and organic, OC carbon) inside and outside the printing office and the beauty salon.

\begin{tabular}{|l|l|l|l|}
\hline \multirow{2}{*}{ Location; PM fraction } & \multirow{2}{*}{ Relation } & \multicolumn{2}{|c|}{$\mathrm{R}^{2}$} \\
\cline { 3 - 4 } & & \multirow{2}{*}{ Printing office } & \multirow{2}{*}{ Beauty salon } \\
\hline \multirow{3}{*}{ Indoor; $\mathrm{PM}_{4}$} & OC $v s$ EC & 0.469 & 0.524 \\
\hline & OC $v s$ PM4 & 0.299 & 0.884 \\
\cline { 2 - 4 } & EC $v s$ PM4 & 0.626 & 0.532 \\
\hline \multirow{3}{*}{ Indoor; TSP } & OC $v s$ EC & 0.195 & 0.761 \\
\cline { 2 - 4 } & OC $v s$ TSP & 0.000 & 0.842 \\
\cline { 2 - 4 } & EC $v s$ TSP & 0.021 & 0.561 \\
\hline
\end{tabular}




\begin{tabular}{|l|l|l|l|}
\hline \multirow{3}{*}{ Indoor $\mathrm{PM}_{4}$ and TSP } & $\mathrm{PM} 4 v s$ TSP & 0.716 & 0.884 \\
\cline { 2 - 4 } & $\mathrm{OC} v s$ OC & 0.238 & 0.876 \\
\cline { 2 - 4 } Indoor and Outdoor; $\mathrm{PM}_{4}$ & $\mathrm{EC} v s$ EC & 0.468 & 0.798 \\
\hline & $\mathrm{PM} 4 v s$ PM4 & 0.015 & 0.030 \\
\cline { 2 - 4 } & $\mathrm{OC} v s$ OC & 0.132 & 0.123 \\
\cline { 2 - 4 } Indoor and Outdoor; TSP & $\mathrm{EC} v s$ EC & 0.042 & 0.216 \\
\hline & $\mathrm{TSP} v s$ TSP & 0.282 & 0.018 \\
\cline { 2 - 4 } & $\mathrm{OC} v s$ OC & 0.082 & 0.020 \\
\cline { 2 - 4 } & $\mathrm{EC} v s$ EC & 0.306 & 0.000 \\
\hline
\end{tabular}

Beside the influence of internal emission sources on the concentrations of PM and PM-bound OC and EC in the printing office and beauty salon, we also examined their impact on the qualitative composition of PM-bound OC, specifically the contribution of $\mathrm{SOC}$ and $\mathrm{POC}$ in the PM-bound OC in the indoor vs. outdoor. Because there is no simple method for separation of SOC and POC in PM-bound OC, 8-h concentrations of TSP- and PM4-bound SOC and POC in indoor and in outdoor air, for both sites, were computed from the formulas [25]:

$\mathrm{POC}=(\mathrm{OC} / \mathrm{EC})_{\min } \times \mathrm{EC}$

$\mathrm{SOC}=\mathrm{OC}-\mathrm{POC}$

where: $\mathrm{OC}$ and EC are 8-h OC and EC concentrations for the same fraction in each location; $(\mathrm{OC} / \mathrm{EC})_{\min }$ is the lowest $\mathrm{OC} / \mathrm{EC}$ for the same fraction in each location.

Both in case of printing office as well as in case of beauty salon the contribution of SOC in the OC was higher in the outdoor than in indoor air; this concerns OC associated with both PM fractions (Fig. 1 and 2). Considerably higher contribution of POC in OC in the indoor air compared to outdoor one, in both analyzed cases, shows the direct influence of PM-bound OC and EC emissions on POC concentrations. The high concentrations of PM-bound EC in both areas contributed, among others, to the fact that the more volatile and semi-volatile compounds from the group of OC was adsorbed onto PM particles (rich in EC concentrations, and having large surface area). In the atmospheric air, during the conditions of strong solar radiation and high air temperature in the summer, these compounds undergo photochemical reactions, and forms the SOC.
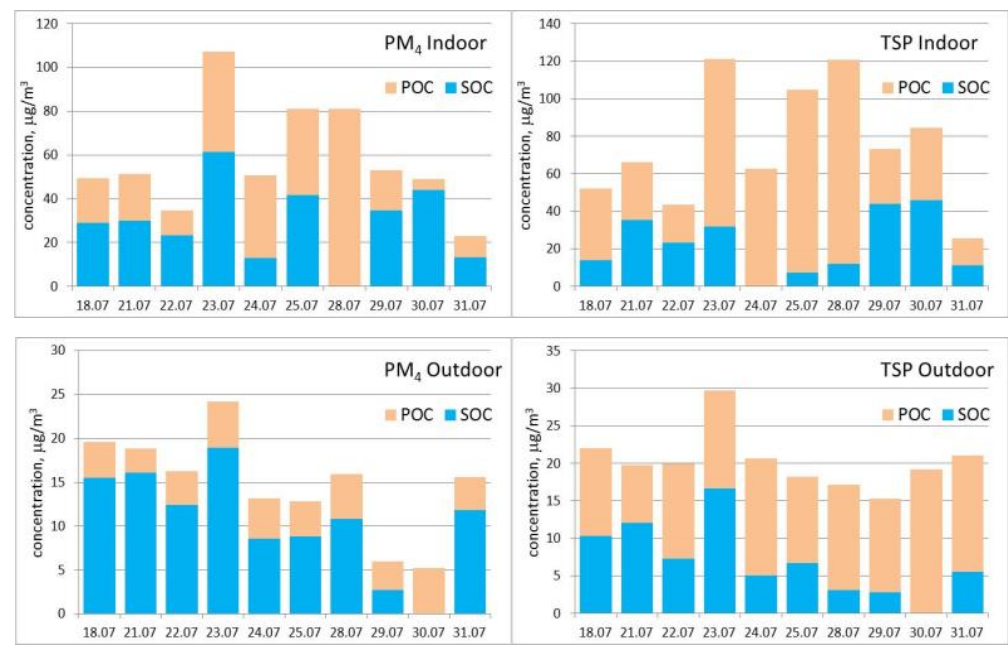

Fig. 1. The 8-h concentrations of SOC and POC in the beauty salon. 


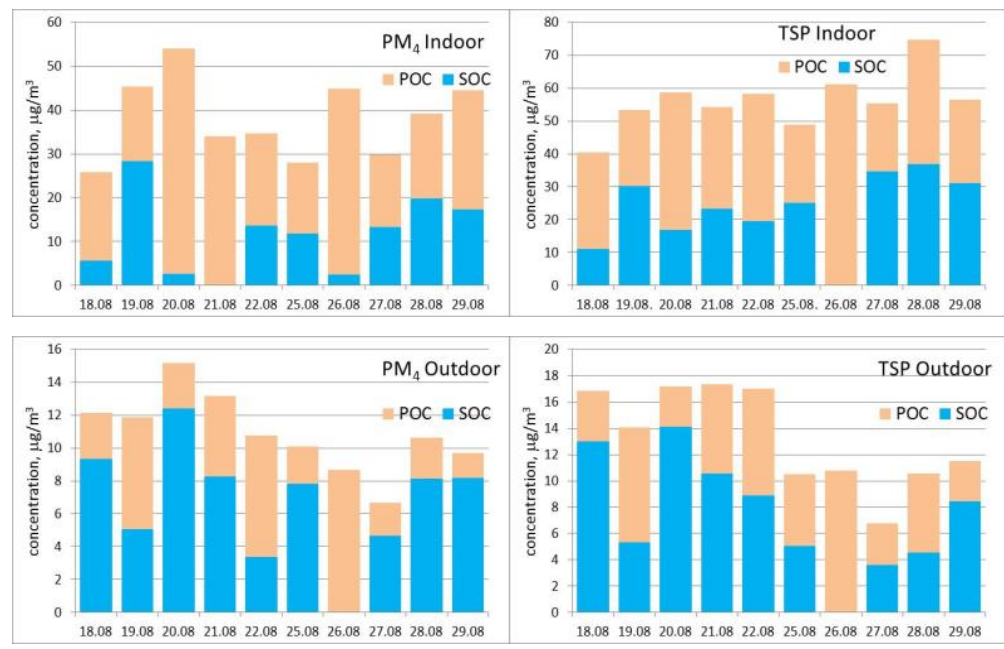

Fig. 2. The 8-h concentrations of SOC and POC in the printing office.

\section{Conclusions}

It has been shown that the indoor concentrations of total particulate matter TSP and the inhalable $\mathrm{PM}_{4}$ fraction in the printing offices and beauty salons, can be very high, and even up to 8 times higher compared to the outdoor ones. In the printing office this could be attributed not only to the internal emissions of PM-bound organic compounds but also due to the mechanical processes of the printing machines working inside such buildings. An increase in the concentrations of PM in the printing office could be also connected with the production of a secondary inorganic aerosol generated by the conversion of nitrogen oxides, ozone and ammonia which are constantly present in such service facilities in very high concentrations. The mentioned phenomena may be although just a seasonal effect (measurements were conducted in a very warm season of the year). In the beauty salons, where human activity is restricted to the hand movement of the beautician an increase in the PM concentrations depends on the emissions of a various substances used during the beauty treatments.

The emissions of organic compounds related to the indoor activities in both service facilities significantly increase the contribution of secondary and primary matter, like SOC and POC in the OC mass. In both facilities, the contribution of POC in OC mass was much greater than in the atmospheric air. This is indirectly due to the relatively high concentrations of EC in the indoor air of both facilities and the adsorption of volatile and semi-volatile organic compounds on the surface of the EC particles.

\section{Acknowledgements}

Work was supported by the DEC-2013/09/N/ST10/04224 project, which was financed by the National Science Center (NCN).

\section{References}

1. J. S. Pastuszka, U. Kyaw Tha Paw, DO. Lis, A. Wlazło, Atmos Environ 34 (2001) 
2. A. Zwoździak, I. Sówka, B. Krupińska, J. Zwoździak, A. Nych, Build Environ 66 (2013)

3. A. Mainka, E. Zajusz-Zubek, K. Kaczmarek, Int J Environ Res Pub He 12 (2015)

4. H. R. Chao, D. E. Que, Y. Y. Gou, C. Y. Chuang, T. Y. Chang, Y. C. Hsu, Aerosol Air Qual Res 16 (2016)

5. M. Oliveira, K. Slezakova, C. Delerue-Matos, M. do Carmo Pereira, S. Morais, Environ Pollut 208 (2016)

6. L. Morawska, T. Salthammer, Indoor environment: airborne particles and settled dust (John Wiley \& Sons, 2006)

7. F. R. Spellman, The Science of Air. Concepts and Applications (Taylor\&Francis Group, 2009)

8. M. Lippman, Environmental toxicants: human, exposures and their health effects (Wiley, 2007)

9. E. Błaszczyk, W. Rogula-Kozłowska, K. Klejnowski, I. Fulara, D. Mielżyńska-Švach, Air Qual Atmos Hlth (2016)

10. G. Majewski, K. Kociszewska, W. Rogula-Kozłowska, H. Pyta, P. Rogula-Kopiec, W. Mucha, J. S. Pastuszka, Atmosphere 7 (2016)

11. W. Rogula-Kozłowska, K. Barbara, K. Krzysztof, S. Szopa, Arch Environ Prot 39 (2013)

12. W. Rogula-Kozłowska, G. Majewski, P.O. Czechowski, Environ Monit Assess 187 (2015)

13. J.S. Pastuszka, W. Rogula-Kozłowska, E. Zajusz-Zubek, Environ Monit Assess 168 (2010)

14. J.S. Pastuszka, W. Rogula-Kozłowska, K. Klejnowski, P. Rogula-Kopiec, Atmosphere 6 (2015)

15. A. Satsangi, T. Pachauri, V. Singla, A. Lakhani, K. M. Kumari, Atmos Res, 113 (2012)

16. K. Klejnowski, B. Błaszczak, A. Krasa, B. Mathews, P. Rogula- Kopiec, W. RogulaKozłowska, [In] Ochrona Powietrza w Teorii i Praktyce (Ed. J. Konieczyński, IPIŚ PAN, 2014)

17. A. M. Jones, R. M. Harrison, Atmos Environ 39 (2005)

18. R. M. Harrison, J. Yin, Sci Total Environ 249 (2000)

19. M. Sillanpää, A. Frey, R. Hillamo, A. S. Pennanen, R. O. Salonen, Atmos Chem Phys 5 (2005)

20. W. F. Rogge, L. M. Hildemann, M. A. Mazurek, G. R. Cass, B. R. Simoneit, Environ Sci Technol 27 (1993)

21. J.H. Seinfeld, S.N. Pandis, Atmospheric chemistry and physics: from air pollution to climate change (John Wiley \& Sons, 2006)

22. Encyclopaedia of Occupational Health and Safety (Ed. J. M. Stellman, International Labour Office, 1998)

23. A. Manoukian, E. Quivet, B. Temime-Roussel, M. Nicolas, F. Maupetit, H. Wortham, Environ Sci Pollut Res 20 (2013)

24. EPA, Candles and Incense as Potential Sources of Indoor Air Pollution: Market Analysis and Literature Review (2001)

25. L.M. Castro, C.A. Pio, R.M. Harrison, DJ.T. Smith, Atmos. Environ. (1999) 